\title{
MRS Bulletin names Lew as Postdoctoral Publication Prize recipient
}

\author{
By Judy Meiksin
}

$M$

RS Bulletin is pleased to announce that Tedrick Thomas Salim Lew of the Institute of Materials Research and Engineering in Singapore has been selected to receive the 2021 MRS Bulletin Postdoctoral Publication Prize.

This award recognizes postdoctoral researchers for their intellectual merit, the impact of their research and scholarship, and their interest in science writing and communications. Tedrick was selected from dozens of well-qualified applicants and nominations for "his excellent academic achievements, passion for his chosen area of research, interest in communicating his research and science to nonscientists, and significant leadership potential in the field of multidisciplinary materials science."

Tedrick is a postdoctoral researcher at the Institute of Materials Research and Engineering, Singapore. He holds a concurrent appointment as an adjunct assistant professor in the Department of Chemical and Biological Engineering at the National University of Singapore. He earned his $\mathrm{PhD}$ degree in chemical engineering in 2020 at the Massachusetts Institute of Technology and his MEng degree in chemical engineering in 2014 at Imperial College London. His research focuses on engineering plant-based technologies by combining approaches from nanotechnology and plant science.

"My vision is to pioneer a new field in which living plants can be considered as biological building blocks for materials scientists," he wrote in his cover letter for the prize, "with the purpose of engineering sustainable technologies."

"One of my research goals is to understand how we can engineer sustainable functional materials from living plants and nanomaterials," says Tedrick. "The advancement of this emerging field of plant nanotechnology will require the support from both the scientific community and the general public. I am very honored to have received the MRS Bulletin Postdoctoral Publication Prize as it provides an ideal platform to share my interest of living plant-based materials with the wider audience."

In an interview with MRS Bulletin, Tedrick said that he remembers when he was growing up, his mother kept a small garden with her favorite vegetables. By observing the plants, she was able to tell whether they needed more fertilizer, water, or sunlight. "I realized I wasn't blessed with her eyes. I couldn't tell just by looking whether the particular plant is healthy or needs more sunlight," Tedrick said. "I've always thought there should be a way to quantify how well these plants are doing." When he began his PhD program and learned about nanoparticle sensors, Tedrick thought about inserting Publication Prize.

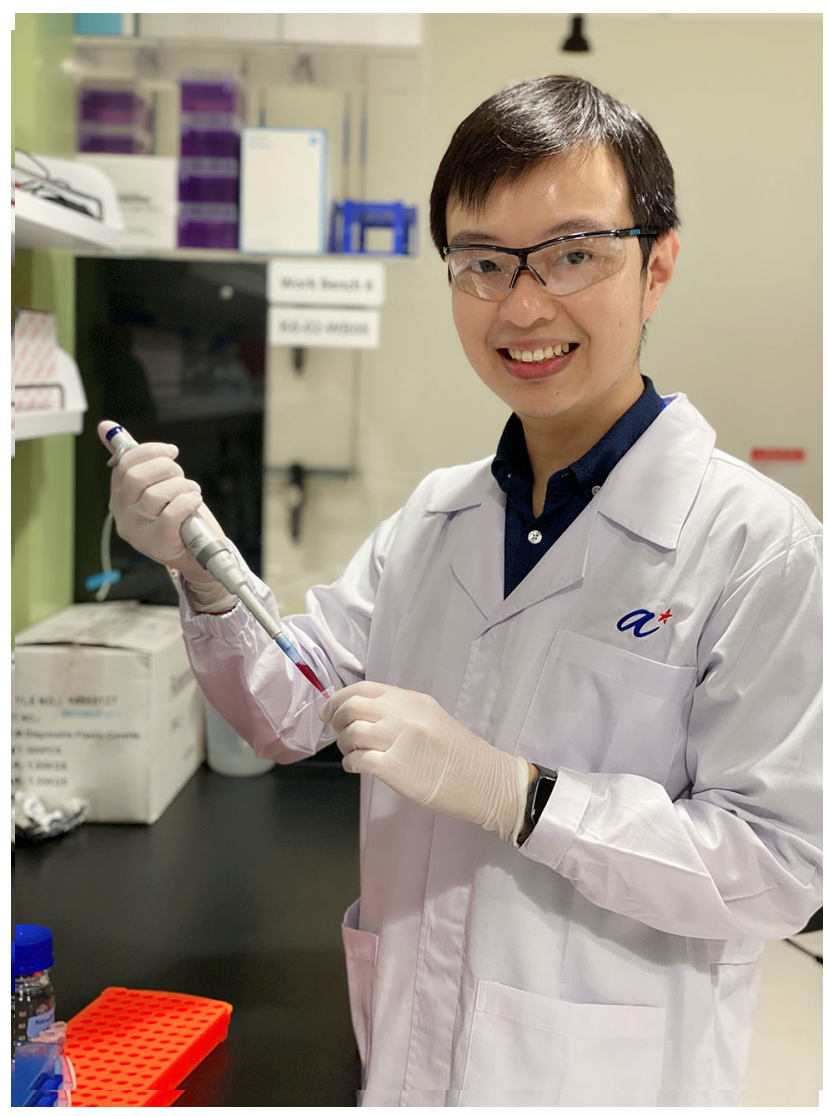

Tedrick Thomas Salim Lew, recipient of the MRS Bulletin Postdoctoral such sensors in plants so that they could, for example, detect a toxic contaminant in the soil, like arsenic.

Thinking more broadly, Tedrick said, "What if the nanoparticles can be engineered to transform plants into something that can actually be functional for us?" In the context of sustainability, such functionalities could include energy harvesting or conversion, or plant materials that could replace plastics for environmental sensors and communication devices. 
In one study, Tedrick developed light-emitting plants where he and his colleagues inserted the enzyme luciferase from fireflies into a plant. By encapsulating luciferase within 10-nm in diameter silica nanoparticles, they were able to direct the insertion within specific compartments of the plant cells. Adenosine triphosphate or ATP is the "energy storage" chemical in plant cells. "When these nanoparticles containing luciferase come into contact with ATP - the energy storage currency within the plants - they can react to give off light emission," he said.

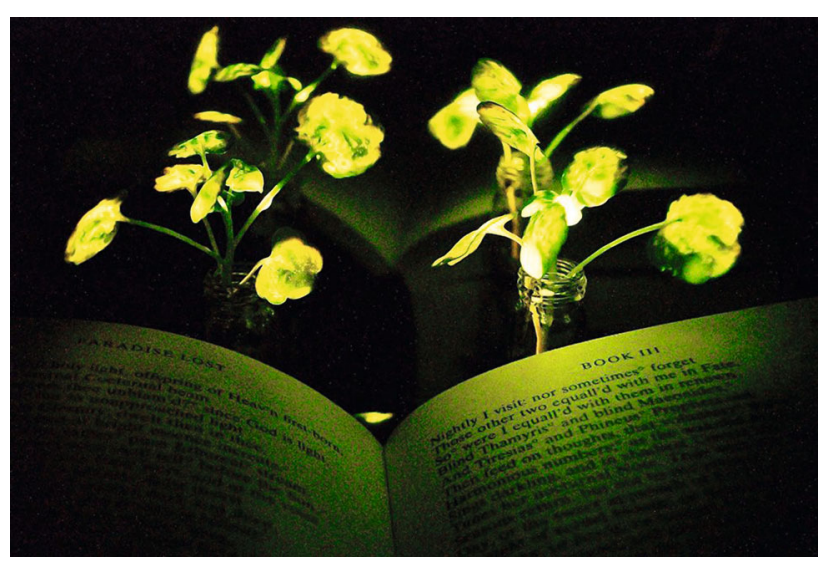

Credit: Seon-Yeong Kwak.
Tedrick and his colleagues actually displayed some of these light-emitting plants at the Smithsonian Design Museum in New York. "We had to transport the plants and the nanoparticles to the museum and then try to make them grow healthily outside of the natural environment," Tedrick said, "but it was worth every effort because I got to interact with different groups of people, from kids to adults."

"There were a few kids who came up to the exhibition and then asked me like 'Oh, this looks like plants from Avatar,' but I didn't watch [the movie] Avatar back then," Tedrick said. In the film, the plants talk to each other, so the exhibit brought the animation closer to reality for the children, he said.

"Most of the adults were more concerned with the food safety issue," he said. They questioned whether the glowing part of the plants would be edible in the future, which provoked Tedrick and his colleagues to think further. The researchers were able to assure the adults that the nanoparticles placed the light-emitting components into parts of the plants that are not edible, ensuring food safety.

Communicating science to the general public requires a lot of experience, Tedrick said. He spends a lot of time discussing his work with friends and family members who are not scientists. $\mathrm{He}$ learned the importance of discussing his research in terms of the "larger picture" such as combining living plants and technology to replace fossil fuels, or to ensure food security for a sustainable world.

The MRS Bulletin Postdoctoral Publication Prize consists of a \$2000 cash award, a profile published in MRS Bulletin, a complimentary one-year membership in the Materials Research Society, and an invitation to publish in MRS Bulletin.

$M R S$ Bulletin is proud to have Tedrick as the recipient of this postdoctoral prize for 2021 .

MRS acknowledges the Jiang Family Foundation and MTI Corporation for their generous contributions to support the Postdoctoral Publication Prize.

\section{MRS DEI Aspiration}

The Materials Research Society embraces diversity, equity and inclusion (DEI) by actively engaging our diverse global membership, supporting the careers of underrepreseanted researchers and investing in community actions to address bias and end inequities.

\section{MRS DIVERSITY, EQUITY AND INCLUSION}

Diversity, equity and inclusion (DEI) at MRS means that all members are encouraged and provided the opportunity to engage with the materials research community and contribute to the future of our field.

This Aspiration reflects our commitment for a welcoming environment in which our members can advance our field with their research and innovations.

MRS is dedicated to engaging members in underrepresented communities through meaningful educational and career opportunities.

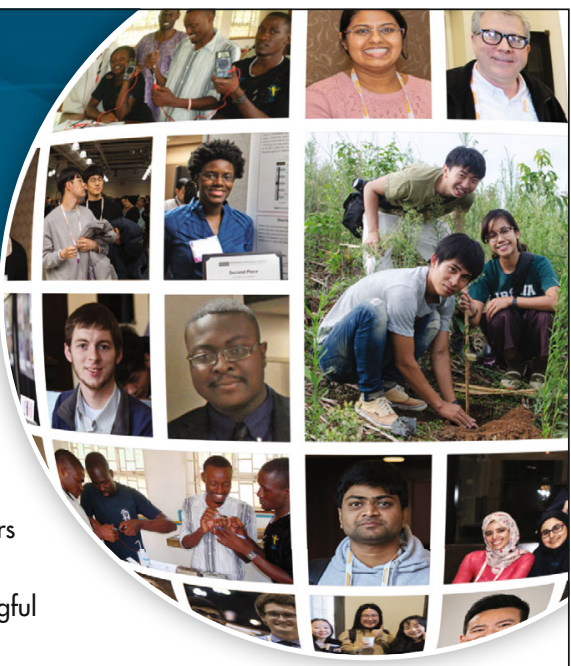

Your contributions are vital to achieving our Aspiration. Please contact mrs.org/contact or volunteer@mrs.org to help MRS make a difference in the materials community. 